\title{
A randomized controlled trial of vitamin $D$ dosing strategies after acute hip fracture: No advantage of loading doses over daily supplementation
}

\author{
Alexandra Papaioannou*, Courtney C Kennedy ${ }^{1}$, Lora Giangregorio² ${ }^{2}$ George loannidis ${ }^{3}$, Janet Pritchard ${ }^{4}$, \\ David A Hanley ${ }^{5}$, Leonardo Farrauto ${ }^{6}$, Justin DeBeer ${ }^{7}$ and Jonathan D Adachi ${ }^{8}$
}

\begin{abstract}
Background: There remains uncertainty regarding the appropriate therapeutic management of hip fracture patients. The primary aim of our study was to examine whether large loading doses in addition to daily vitamin D offered any advantage over a simple daily low-dose vitamin D regimen for increasing vitamin D levels.

Methods: In this randomized controlled study, patients over age 50 with an acute fragility hip fracture were enrolled from two hospital sites in Ontario, Canada. Participants were randomized to one of three loading dose groups: placebo; 50,000 IU vitamin $D_{2}$; or 100,000 IU $D_{2}$. Following a placebo/loading dose, all patients received a daily tablet of 1,000 IU vitamin $\mathrm{D}_{3}$ for 90 days. Serum 25-hydroxy vitamin D (25-OHD) was measured at baseline, discharge from acute care (approximately 4-weeks), and 3-months.

Results: Sixty-five patients were enrolled in the study (44\% male). An immediate rise in 25-OHD occurred in the 100,000 group, however there were no significant differences in 25-OHD between the placebo, 50,000 and 100,000 loading dose groups after 4-weeks $(69.3,84.5,75.6 \mathrm{nmol} / \mathrm{L}, \mathrm{P}=0.15)$ and 3 -months $(86.7,84.2,73.3 \mathrm{nmol} / \mathrm{L}, \mathrm{p}=$ 0.09), respectively. At the end of the study, approximately $75 \%$ of the placebo and 50,000 groups had reached the target therapeutic range $(75 \mathrm{nmol} / \mathrm{L})$, and $44 \%$ of the 100,000 group.

Conclusions: In correcting vitamin D insufficiency/deficiency in elderly patients with hip fracture, our findings suggest that starting with a lower daily dose of Vitamin $D_{3}$ achieved similar results as providing an additional large loading dose of Vitamin $D_{2}$. At the end of the study, all three groups were equally effective in attaining improvement in 25-OHD levels. Given that a daily dose of 1,000 IU vitamin $\mathrm{D}_{3}$ (with or without a loading dose) resulted in at least $25 \%$ of patients having suboptimal vitamin D status, patients with acute hip fracture may benefit from a higher daily dose of vitamin D.
\end{abstract}

Trial registration: Clinical Trials \# NCT00424619

\section{Background}

Vitamin D deficiency is a major risk factor for accelerated bone loss and fracture [1]. Insufficient vitamin D levels lead to reduced calcium absorption (particularly at low-to-moderate calcium intakes), elevated serum parathyroid hormone, and increased rates of bone resorption, which over time may lead to bone fracture [2]. The optimal level of serum 25-hydroxyvitamin $\mathrm{D}_{3}$ (25-OHD)

\footnotetext{
* Correspondence: papaioannou@hhsc.ca

'McMaster University, HHSC, St. Peter's Hospital Juravinski Research Centre,

88 Maplewood Avenue Hamilton, ON L8M 1W9, Canada

Full list of author information is available at the end of the article
}

for bone health has been defined by a consensus panel as $75 \mathrm{nmol} / \mathrm{L}$ [3]. This level has also been endorsed by Osteoporosis Canada [4] and the International Osteoporosis Foundation [5].

There is evidence from a number of meta-analyses that supplementation with at least 800 to $1,000 \mathrm{IU} /$ day vitamin $\mathrm{D}_{3}$ reduces fractures [6,7] and falls [8]. The level of serum 25-OHD achieved is also an important consideration. It has been demonstrated that falls and fracture reductions are more consistently achieved when serum 25-OHD levels are at least $60 \mathrm{nmol} / \mathrm{L}$ and 75 $\mathrm{nmol} / \mathrm{L}$, respectively [9-11].

\section{C) Biomed Central}


Patients with hip fracture are at high risk for a recurrent hip fracture or other fragility fractures [12] and should be targeted for osteoporosis treatment (i.e. bisphosphonate or other antiresorptive). Before hip fracture patients are initiated on bisphosphonate therapy, an important consideration is whether 25-OHD is at a therapeutic level $[13,14]$. The majority of patients with hip fracture have been found to have lower serum concentrations of 25-OHD than those without a fracture [15-19].

There remains uncertainly regarding the appropriate management of hip fracture patients in the acute fracture period, particularly for patients who are severely vitamin D deficient. Several studies have examined various vitamin $\mathrm{D}$ dosing strategies in patients with fractures and/or elderly cohorts [20-24]. However, the focus of previous studies was comparing the timing of dosing (i.e., daily versus weekly versus monthly). Whether supplementing patients with a large loading dose of vitamin $\mathrm{D}_{2}$ in addition to daily vitamin $\mathrm{D}_{3}$ offers any advantage over simply prescribing daily vitamin $\mathrm{D}_{3}$ is yet to be determined. Thus, the primary aim of our study was to compare change in 25-OHD levels after supplementation with daily vitamin $\mathrm{D}_{3}$ plus one of three loading dosing regimens: 1) placebo bolus 2) 50,000 IU vitamin $D_{2}$ 3) 100,000 IU vitamin $D_{2}$.

\section{Methods}

\section{Participants}

Between October 2007 and April 2009, consenting and eligible patients over age 50 with an acute fragility hip fracture (defined as femoral neck, trochanteric, subtrochanteric or subcapital) which was the result of a minimal trauma accident, defined as a fall from standing height or less, were enrolled from two large academic hospital sites in Hamilton, Ontario, Canada. Patients were not eligible if they had pelvic fractures; pathological fractures secondary to malignancy or intrinsic bone disease (e.g. Paget's disease); pre-existing bone abnormality; cancer in the past 10 years likely to metastasize to bone; renal insufficiency (creatinine $<30 \mathrm{mls} / \mathrm{min}$ ); renal stones in past 10 years; hypercalcemia (primary hyperparathyroidism; granulomatous diseases); hypocalcemia; stroke within the last 3 months; or had taken hormone replacement therapy, calcitonin, bisphosphonates, raloxifen, or parathyroid hormone during the previous 24 months. Patients admitted from long-term care facilities/nursing homes were also excluded.

\section{Study Protocol}

This was a parallel, double-blind, randomized controlled study. The central in-patient pharmacy at McMaster University Medical Centre coordinated the randomization procedure and the distribution of study drugs.
Patients were randomized in blocks according to a computer-generated randomization list. The medication treatment group was concealed and all participants, study coordinators, physicians, staff, and caregivers were blinded to treatment group allocation. An overview of the study was provided to potential participants by surgical staff during routine examination (prior to or following hip fracture repair). Study coordinators followedup with patient enrolment and informed consent within 7 days pre or post-operatively.

Participants were randomized to one of three groups which differed only by the oral bolus loading dose received on day 1: placebo bolus, 50,000 IU vitamin $D_{2}$, or $100,000 \mathrm{IU}$ vitamin $\mathrm{D}_{2}$. Following the one-time bolus dose at baseline, patients in all groups received a daily tablet of 1,000 IU vitamin $\mathrm{D}_{3}$ for 90 days. Vitamin D bolus doses and tablets were dispensed by nursing staff while in-hospital. Prior to discharge from hospital, study coordinators provided participants with the remainder of the $1,000 \mathrm{IU}$ vitamin $\mathrm{D}_{3}$ tablets to be taken daily and reviewed medication instructions. Additional daily vitamin $D_{3}(1,000 \mathrm{IU})$ pills were provided to participants if their 3-month examination date was extended. Adherence data for the inpatient period was provided by the hospital pharmacist, and pill counts for the post-discharge period were conducted at the 3-month clinic appointment by the study coordinators. Adherence was defined as taking at least $80 \%$ of dispensed daily vitamin $\mathrm{D}_{3}$ pills.

Vitamin $D_{3}$ (cholecalciferol) is the molecule that is synthesized in the skin in response to ultraviolet $\mathrm{B}$ light exposure, while vitamin $\mathrm{D}_{2}$ (ergocalciferol) is derived from irradiation of certain fungi. Both vitamin $\mathrm{D}_{2}$ and vitamin $\mathrm{D}_{3}$ go through the stages of metabolism to create the active form of vitamin $\mathrm{D}$ (1,25-dihydroxyvitamin $\mathrm{D})$, there is support that vitamin $\mathrm{D}_{2}$ may not be used as efficiently as vitamin $\mathrm{D}_{3}$ in human physiology [25-27].

\section{Study Measures Laboratory}

Serum 25-OHD was measured at baseline, discharge from acute care at approximately 4-weeks, and at a follow-up study visit at approximately 3 -months. The measurements may have been several days from the actual 4-week $($ mean $=26.3$, standard deviation $=7.9)$ and 3 month $($ mean $=99.0$, standard deviation $=25.0)$ time points but for simplicity they will be referred to as "4weeks" and " 3 months" throughout the paper. Baseline blood samples were drawn in-hospital; additional venipunctures were performed prior to hospital discharge, and at 3-months either in-hospital (for patients remaining in acute care or rehabilitation) or at the out-patient clinic visit. In addition to 25-OHD, serum calcium, parathyroid hormone (PTH), phosphate, albumin, alkaline 
phosphatase, hemoglobin, and creatinine were assessed at baseline.

Serum 25-OHD was analyzed with the DiaSorin, 25hydroxyvitamin D radioimmunoassay (Stillwater, Minnesota 55082-0285, U.S.A). The central laboratory analyzed all 25-OHD tests with the exception of three patients who had their final 25-OHD analyzed at alternate laboratories for logistical reasons.

Clinical and demographic characteristics were abstracted from the patient chart and obtained from a patient or family interview for the purpose of describing the population, and included living situation, fracture history, family fracture history, ambulation status and aids, number medications, co-morbidities and bisphosphonate use. The Charlson Index [28] was also calculated, based on 19 categories of co-morbidity (defined by ICD-9-CM diagnosis and procedure codes) which are weighted and tabulated into an overall co-morbidity score. A higher score indicates greater disease burden. Height and weight were abstracted from the patient's chart or measured at the 3-month clinic appointment. This research was conducted in compliance with the Helsinki declaration and ethics approval was received from the Hamilton Health Sciences/McMaster University Faculty of Health Sciences Research Ethics Board. The Data Safety Monitoring Committee reviewed all adverse events.

\section{Statistical Analysis}

We reported the results in accordance with the Consolidated Standards of Reporting Trials (CONSORT) criteria [29]. Study data were entered and managed using an ACCESS database (Microsoft Access 2000). Analyses were performed with SPSS v.18 (SPSS Inc. Chicago, Illinois) software package and SAS/Stat 9.1 (SAS Institute Inc., Cary, North Carolina). All analyses were intention to treat and included all available data (unless specified in sub-group analyses). Descriptive data are presented as means, standard deviation (SD), 95\% confidence intervals (95\% CI) for continuous variables and as proportions and percents for categorical data. Any outliers above or below 3 standard deviations were checked against original laboratory reports or chart documents. Box plots were constructed to display the distributions of 25-OHD values.

Baseline data were compared according to treatment groups using one-way ANOVA; Post hoc pairwise comparisons were made using Bonferroni tests. Pearson's chi-square or Fisher's exact tests were used to examine categorical variables as appropriate.

ANCOVA analyses were used to compare differences between groups on 25-OHD and functional measures, adjusting for relevant variables. To account for variation in when 25-OHD measures were collected, we controlled for time to measure (i.e. days from bolus administration to a 25-OHD measure). Multivariable linear regression analysis was used to examine the percent change in 25-OHD $\left[\left(\frac{\text { post }- \text { pre }}{\text { pre }}\right) * 100\right]$ between baseline and follow-up measures, adjusting for time to measure and baseline 25-OHD scores. The proportion of patients reaching the target 25-OHD therapeutic level $(\geq 75 \mathrm{nmol} / \mathrm{L}$ ) was also calculated and compared between groups using chi-square analysis. The criterion for statistical significance was set at alpha $=0.05$.

\section{Results}

Of 626 patients screened for eligibility, 110 patients were approached to participate in the study as displayed in the CONSORT diagram (Figure 1). Of these, 45 denied consent and 65 were enrolled. Twenty-one of 65 (32\%) patients were randomized to the placebo group, and 22 of $65(34 \%)$ patients each to the 50,000 IU vitamin $\mathrm{D}_{2}$, and 100,000 IU vitamin $\mathrm{D}_{2}$ loading dose groups, respectively. One participant randomized to the placebo group was a screen failure (due to errantly receiving post-operative orders for vitamin D) and no data was collected on this patient.

Table 1 presents baseline clinical and laboratory characteristics. The mean age of the 100,000 group was significantly lower than the 50,000 group $(\mathrm{p}=0.024)$. This is likely explained by the greater proportion of men in the 100,000 group as the men enrolled in our study tended to be younger than women (Table 1). Overall, 36 of 65 study participants (56\%) were female. Fourteen of 65 participants (21\%) had a previous atraumatic fracture after the age of 40 years documented, and $62 \%$ were ambulatory without aids prior to hip fracture.

The box plots in Figure 2 illustrate the distribution of serum 25-OHD values by treatment group at 4-weeks and 3-months. There were no significant differences in mean serum 25-OHD between groups at 4-weeks or 3-months (Table 2). By 4-weeks, 47-59\% of patients had reached the target therapeutic range $(\geq 75 \mathrm{nmol} / \mathrm{L})$. By 3 -months, approximately $75 \%$ of the placebo and 50,000 groups had reached therapeutic range, and only $44 \%$ of the 100,000 group, but the difference between groups in the proportion of patients in the therapeutic range was not statistically significant (Table 2).

In some cases, it was not possible to obtain a baseline serum sample until after the bolus dose. However, this limitation in timing allowed us to provide a descriptive comparison of the immediate effects of the dosing regimens. In this sub-group $(\mathrm{n}=25)$ who had 25-OHD measured 1-3 days after administration of the bolus dose, there appeared to be an immediate rise in serum 


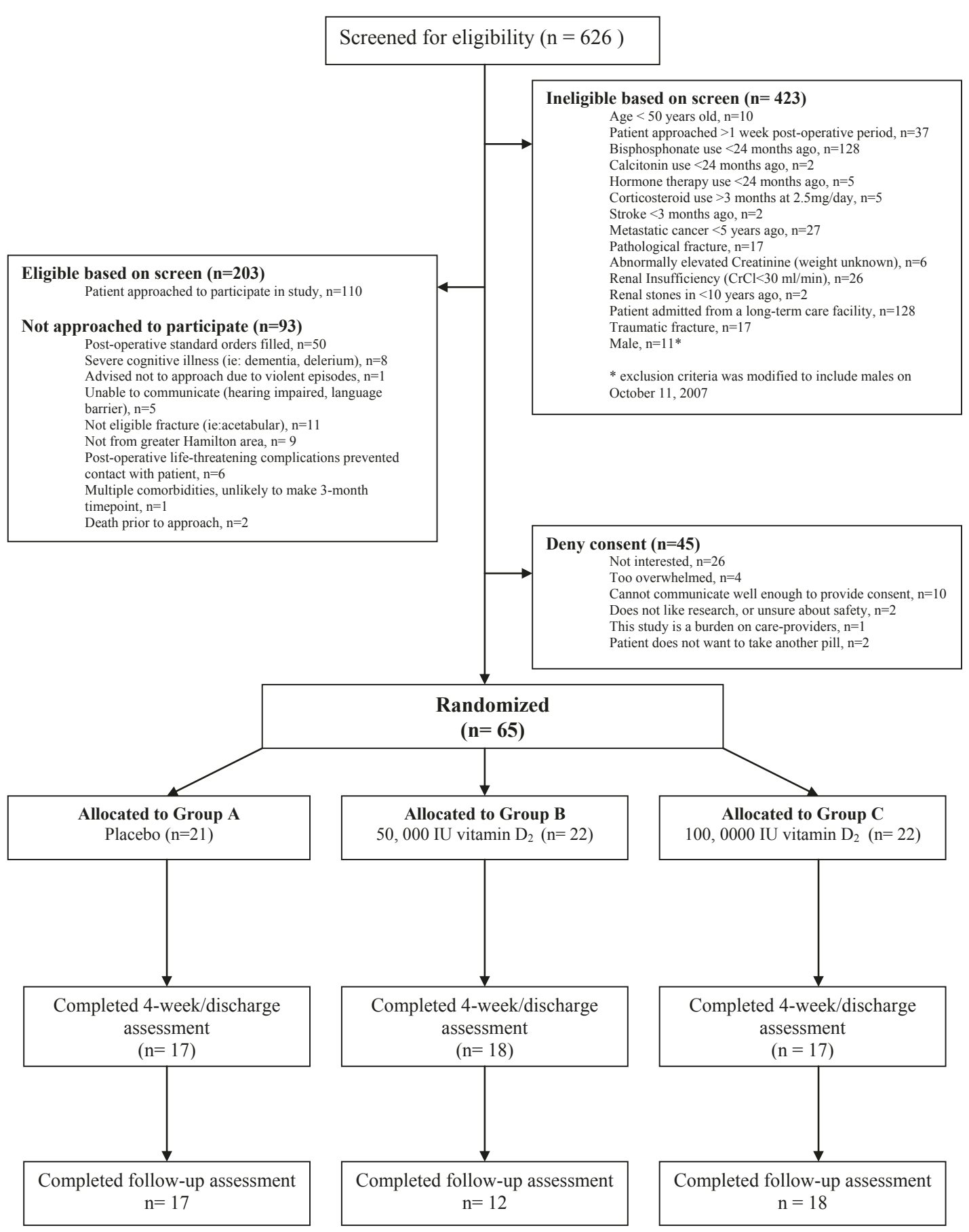

Figure 1 Patients Screened.

25-OHD for patients taking the two loading doses, but the difference was only significant for the 100,000 vitamin $\mathrm{D}_{2}$ group compared with the placebo group (76.0 $\mathrm{nmol} / \mathrm{L}$ versus $41.6 \mathrm{nmol} / \mathrm{L}, \mathrm{p}=0.03$, Table 2 ).

In multiple linear regression analysis, controlling for time (between bolus dose and 25-OHD measures) and baseline 25-OHD, the percent change in 25-OHD was not significantly different between the treatment arms at 4-weeks or 3-months (data not shown). The mean percent change over 4-weeks was $43.3 \%$ (95\% CI -0.29 , 86.8), $100.3 \%$ (95\% CI 59.3, 141.3), and $82.5 \%$ (95\% CI $40.5,124.5)$ for the placebo, 50,000 and 100,000 groups 
Table 1 Characteristics of study sample at baseline, according to treatment allocation ${ }^{\dagger}$

\begin{tabular}{|c|c|c|c|c|}
\hline & $\begin{array}{c}\text { Placebo } \\
\mathrm{n}=\mathbf{2 1}\end{array}$ & $\begin{array}{l}50,000 \\
n=22 \\
\end{array}$ & $\begin{array}{c}100,000 \\
n=22\end{array}$ & Missing Cases (Placebo/50,000/100,000) \\
\hline Age in years & $78.5(10.3)$ & $82.9(8.7) *$ & $73.9(12.4) *$ & $1 / 0 / 0$ \\
\hline Male (SD) & $77.9(8.4)$ & $77.9(11.2)$ & $69.5(12.9)$ & \\
\hline Female (SD) & $78.8(11.5)$ & $85.2(6.4)$ & $81.7(6.6)$ & \\
\hline Gender & & & & $1 / 0 / 0$ \\
\hline Male (\%) & $7(35)$ & $7(32)$ & $14(64)$ & \\
\hline Female (\%) & $13(65)$ & $15(68)$ & $8(36)$ & \\
\hline Height, cm & $163.8(11.4)$ & $162.9(10.1)$ & $169.7(12.6)$ & $2 / 3 / 2$ \\
\hline Male (SD) & $174.8(10.2)$ & $173.5(4.7)$ & $175.0(10.3)$ & \\
\hline Female (SD) & $158.7(7.9)$ & $156.7(6.3)$ & $158.2(7.3)$ & \\
\hline Weight, kg & $70.6(25.4)$ & $64.8(18.1)$ & $72.1(15.8)$ & $2 / 2 / 2$ \\
\hline Male (SD) & $89.1(30.3)$ & $79.4(12.7)$ & $76.1(10.8)$ & \\
\hline Female (SD) & $62.1(18.4)$ & $57.0(15.8)$ & $64.6(21.4)$ & \\
\hline Prior Smoking (\%) & $9(50)$ & $7(39)$ & $11(58)$ & $3 / 4 / 3$ \\
\hline Previous fracture documented (\%) & $3(15)$ & $5(23)$ & $6(27)$ & $1 / 0 / 0$ \\
\hline Prior vitamin D use (\%) & $4(20)$ & $1(4.5)$ & $4(18)$ & $1 / 0 / 0$ \\
\hline Prior calcium use (\%) & $5(25)$ & $2(9)$ & $4(18)$ & $1 / 0 / 0$ \\
\hline Number of medications at admission (SD) & $6.2(4.6)$ & $6.0(3.8)$ & $5.0(4.4)$ & $1 / 0 / 0$ \\
\hline Charlson index (SD) & $1.30(1.13)$ & $0.82(1.18)$ & $0.55(0.80)$ & $2 / 0 / 0$ \\
\hline Ambulatory without aids prior to admission (\%) & $8(44)$ & $13(72)$ & $13(68)$ & $3 / 4 / 3$ \\
\hline Total calcium, mmol/L (SD) & $2.10(0.14)$ & $2.12(0.11)$ & $2.08(0.14)$ & $1 / 1 / 0$ \\
\hline $\mathrm{Hb}, \mathrm{g} / \mathrm{L}(\mathrm{SD})$ & $108.6(15.2)$ & $102.2(14.3)$ & $107.9(17.4)$ & $1 / 0 / 0$ \\
\hline Albumin, g/L (SD) & $34.1(6.0)$ & $33.0(5.8)$ & $32.4(5.4)$ & $1 / 5 / 4$ \\
\hline Creatinine, umol/L (SD) & $73.7(37.0)$ & $70.5(23.8)$ & $77.4(26.1)$ & $1 / 0 / 0$ \\
\hline Phosphate, mmol/L (SD) & $0.94(0.27)$ & $0.86(0.22)$ & $0.97(0.24)$ & $1 / 0 / 0$ \\
\hline Alkaline phosphatase, U/L (SD) & $98.6(37.8)$ & $78.7(26.2)$ & $79.4(51.1)$ & $1 / 0 / 0$ \\
\hline Parathyroid Hormone (PTH), pmol/L (SD) & $4.20(2.12)$ & $5.35(3.01)$ & $5.10(3.91)$ & $1 / 0 / 0$ \\
\hline
\end{tabular}

*Significant difference between groups, $\mathrm{p}<0.05$.

${ }^{\dagger}$ Refers to loading dose of vitamin $D_{2}$ at baseline; all groups received 1,000 IU vitamin $D_{3}$ /daily following loading dose.

Values are the mean (SD), or number (\%)

respectively. Over approximately 3-months, the mean percent change was $85.6 \%$ (95\% CI 30.2, 141.0), 146.1\% (95\% CI 83.8, 208.4), and 68.1\% (95\% CI 17.1, 119.1).

\section{Safety}

Five serious adverse events were reported: one in the placebo group, two in the 50,000 group, and two in the 100,000 group. The serious adverse events were: 2 deaths, 1 fractured hip, 1 pulmonary edema and myocardial infarction, 1 gangrenous left foot requiring amputation. All were judged unrelated to the study treatments by the Data Safety Monitoring Board.

\section{Adherence}

Of the 64 patients who received study medication while in-hospital (until discharge to home/long-term care, study withdrawal, or death), 54 participants (83\%) were adherent to daily $1,000 \mathrm{IU}$ vitamin $\mathrm{D}_{3}$ (ie:, consumed at least $80 \%$ of tablets). The mean (SD) in-hospital compliance in the placebo, 50,000 IU and 100,000 IU vitamin $\mathrm{D}_{2}$ groups were 97.1 (7.6\%), 86.8 (16.2\%) and $89.5(12.5 \%)$, respectively $(\mathrm{p}=0.033)$. Of 47 participants who completed the final 25-OHD assessment, four participants (8\%) completed the study in-hospital and are included in the above in-hospital adherence rate, and 13 (28\%) did not bring their study pills to their clinic visit. Of the remaining participants who attended the final study visit, the mean (SD) at home compliance for those in the placebo, 50,000 IU and 100,000 IU vitamin $\mathrm{D}_{2}$ groups were $84(14.5 \%), 96.1$ (9.3\%) and 91.8 (15.2\%), respectively $(\mathrm{p}=0.270)$.

\section{Discussion}

Our findings reveal that daily vitamin $\mathrm{D}_{3}$ with or without a loading dose improves serum 25-OHD levels and that this result was seen as early as 4-weeks. Further, there were no significant differences in 25-OHD values between loading dose groups after 4-weeks or 3-months 

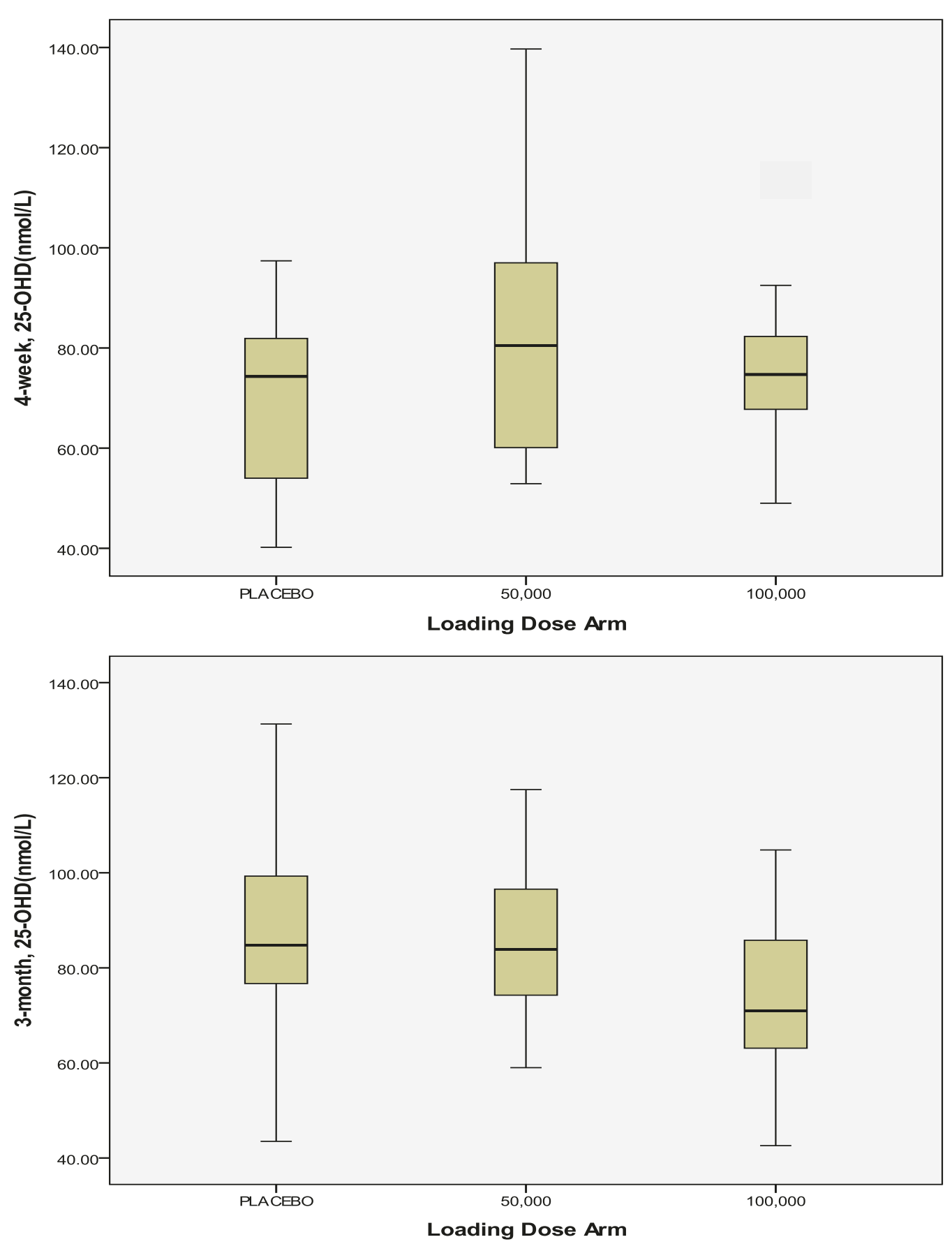

Figure 2 Distribution of serum 25-OHD values by treatment group at Week 4 and 3 months.

of daily 1,000 IU vitamin $\mathrm{D}_{3}$ therapy. Despite the significant increase in 25-OHD levels for all three groups, 1 in 4 participants in the placebo and 50,000 groups and 1 in 2 participants in the 100,000 group did not achieve the target therapeutic level $(\geq 75 \mathrm{nmol} / \mathrm{L})$ by 3 -months. While not significantly different from the other two groups, the low number of participants in the 100,000 groups that did achieve the therapeutic level is an interesting finding and needs further investigation. Our findings suggest that daily 1,000 IU vitamin $D_{3}$ may be nearly as or equally effective as providing an additional large loading dose of vitamin $\mathrm{D}_{2}$ for improving vitamin $\mathrm{D}$ levels in hip fracture patients, but many patients may still not achieve the therapeutic target. A daily dose of 
Table 2 Mean (95\% Cl) 25-OHD and percent reaching $75 \mathrm{nmol} / \mathrm{L}(\mathrm{N}=65)$

\begin{tabular}{|c|c|c|c|c|}
\hline & Placebo & 50,000 & 100,000 & p-value \\
\hline \multicolumn{5}{|l|}{ Baseline $(n=59)$} \\
\hline \multicolumn{5}{|l|}{ Mean 25-OHD, unadjusted } \\
\hline serum collection at -3 to 0 days, $\mathrm{n}=34$ & $\begin{array}{c}58.7(43.4-74.0) \\
n=7\end{array}$ & $\begin{array}{c}52.3(37.4-67.2) \\
n=14\end{array}$ & $\begin{array}{c}44.3(30.8-57.8) \\
n=13\end{array}$ & 0.39 \\
\hline serum collection at days $1-3, n=25$ & $\begin{array}{c}41.6(29.3-53.9) \\
n=11\end{array}$ & $\begin{array}{c}59.0(28.4-89.6) \\
n=6\end{array}$ & $\begin{array}{c}76.0(49.1-102.8) \\
n=8\end{array}$ & $0.03^{+}$ \\
\hline Mean 25-OHD, adjusted for time to measure, $n=59^{\ddagger}$ & $\begin{array}{c}46.7(34.8-58.6) \\
n=18)\end{array}$ & $\begin{array}{c}53.5(42.3-64.8) \\
n=20\end{array}$ & $\begin{array}{c}58.4(47.3-69.5) \\
n=21\end{array}$ & 0.37 \\
\hline \multicolumn{5}{|l|}{ 4-week $(n=50)$} \\
\hline Mean 25-OHD, unadjusted & $\begin{array}{c}69.8(59.8-79.8) \\
n=17\end{array}$ & $\begin{array}{c}84.1(69.3-98.9) \\
n=17\end{array}$ & $\begin{array}{c}75.6(67.6-83.6) \\
n=16\end{array}$ & 0.17 \\
\hline Mean $25-\mathrm{OHD}$, adjusted for time to measure* & $\begin{array}{c}69.3(58.4-80.2) \\
n=17\end{array}$ & $\begin{array}{c}84.5(73.7-95.3) \\
n=17\end{array}$ & $\begin{array}{c}75.6(64.5-86.8) \\
n=16\end{array}$ & 0.15 \\
\hline Proportion $\geq 75 \mathrm{nmol} / \mathrm{L}$ & $47.1 \%$ & $58.8 \%$ & $50.0 \%$ & 0.76 \\
\hline \multicolumn{5}{|l|}{ 3-month $(n=47)$} \\
\hline Unadjusted & $\begin{array}{c}85.0(73.6-93.3) \\
n=17\end{array}$ & $\begin{array}{c}85.2(74.5-95.9) \\
n=12\end{array}$ & $\begin{array}{c}74.3(66.1-82.5) \\
n=18\end{array}$ & 0.17 \\
\hline Mean 25-OHD, adjusted for time to measure** & $\begin{array}{c}86.7(77.6-95.9) \\
n=17\end{array}$ & $\begin{array}{c}84.2(73.6-94.9) \\
n=12\end{array}$ & $\begin{array}{c}73.3(64.5-82.1) \\
n=18\end{array}$ & 0.09 \\
\hline Proportion $\geq 75 \mathrm{nmol} / \mathrm{L}$ & $76.5 \%$ & $75 \%$ & $44.4 \%$ & 0.09 \\
\hline
\end{tabular}

Baseline data $(n=59)$ was missing for two participants, and four outliers with 25-OHD taken at 6,10 or 12 days were not included. 4-week data $(n=50)$ was missing for 13 participants, and two outliers with $25-\mathrm{OHD}$ taken at $<13$ days were not included. 3-month data $(n=47)$ was missing for 18 participants.

${ }^{\dagger}$ Significant difference between 100,000 and placebo (post-hoc). ${ }^{\ddagger}$ Mean time between bolus vitamin D dose and baseline $25-\mathrm{OHD}$ measure was 0.36 days. ${ }^{*}$ Mean time between bolus vitamin $\mathrm{D}$ dose and $25-\mathrm{OHD}$ at second measure was 28.1 days. ${ }^{* *}$ Mean time between bolus vitamin $\mathrm{D}$ dose and $25-\mathrm{OHD}$ at third measure was 98.9 days.

2,000 IU vitamin $\mathrm{D}_{3}$ may be a better choice for this group of patients.

Daily vitamin D administration is at least as effective at elevating serum 25-OHD levels as compared with higher doses of vitamin D administered less frequently. In one study [22], after 8-weeks, no significant differences were found in serum 25-OHD levels for daily $\left(1,500 \mathrm{IU}\right.$ vitamin $\left.\mathrm{D}_{3}\right)$, weekly $\left(10,500 \mathrm{IU}\right.$ vitamin $\left.\mathrm{D}_{3}\right)$ or monthly (45,000 IU vitamin $\mathrm{D}_{3}$ ) dosing in 48 hip fracture patients. In addition, other investigators have demonstrated that a high does regimen of cholecalciferol 50, 000 IU daily for 10 days versus continuous low-dose cholecalciferol regimen of 3000 IU daily for 30 days, followed by 1000 IU daily for 60 days were both effective in increasing serum 25-OHD levels [30]. In a study of 40 elderly women, Pekkarinin et al. [20] found that daily $800 \mathrm{IU}$ vitamin $\mathrm{D}_{3}$ was more effective in increasing serum 25-OHD levels than 97,333 IU vitamin $\mathrm{D}_{3}$ every four months (treatment groups were equivalent in terms of cumulative annual dose). In a cohort of elderly women with hip fractures, a group taking oral 800 IU vitamin $\mathrm{D}_{3}$ daily had similar 25-OHD after 12months as a group taking a single injection of 300,000 IU of vitamin $\mathrm{D}_{2}$ (50 vs. $40 \mathrm{nmol} / \mathrm{L}$ ) [31]. In a 4-month study of 338 elderly nursing home residents [23], daily 600 IU vitamin $D_{3}$ was more effective than weekly 4200 IU vitamin $\mathrm{D}_{3}$ or monthly 18,000 IU vitamin $\mathrm{D}_{3}$ doses. While others investigators have found that daily regimens are at least as effective as monthly or weekly regimens assuming the same cumulative dose, our study is the first to show that providing a one time, large dose of vitamin $\mathrm{D}_{2}$ prior to daily vitamin $\mathrm{D}_{3}$ supplementation was not advantageous with respect to achieving optimal 25-OHD levels after several weeks.

In a sub-group of patients who were tested 1-3 days after receiving either the placebo or loading dose, an almost immediate rise in 25-OHD was observed in the loading dose groups compared with placebo, which was statistically significant for the 100,000 group. Other studies have seen similar initial increases in 25-OHD after large doses of vitamin $\mathrm{D}_{3}$ [45,000 IU [22]; 300,000 IU [32]] and vitamin $\mathrm{D}_{2}$ [300,000 IU [32]]. In a study with frail elderly patients, a loading dose of 500,000 IU vitamin $D_{3}$ (without daily maintenance therapy) resulted in a rapid increase in 25-OHD in the first month, but progressively decreased reaching a mean of $59 \mathrm{nmol} / \mathrm{L}$ by 9-months [24]. In our study we found no significant differences in 25-OHD levels between groups after 4 weeks or 3 months after the placebo/vitamin $\mathrm{D}_{2}$ loading. It is possible that a large loading dose may not be as effective for long-term maintenance of optimal vitamin D levels because the large dose may induce increased 24-hydroxylase, causing an increased catabolism of both 25-OHD and $1,25-(\mathrm{OH})_{2}$ vitamin $\mathrm{D}$. Therefore, less substrate is available for the production of $1,25-(\mathrm{OH})_{2}$ vitamin $\mathrm{D}$, the biologically active form of vitamin $\mathrm{D}$, and when 
produced it is more rapidly degraded. Our study suggests that a regimen of 1,000 IU vitamin D daily is as effective as vitamin D daily plus one loading dose, but further research is required to confirm whether the loading dose provides a benefit prior to the 4-week time point.

Our study demonstrated low 25-OHD levels in hip fracture patients. In addition, other investigators have found even lower serum levels, which highlights the need for vitamin D supplementations [33]. A key finding in the current study was that many patients had not achieved the therapeutic target of $75 \mathrm{nmol} / \mathrm{L}$ at the 3month time-point. Previous studies comparing daily to weekly or monthly regimens have also reported suboptimal vitamin D levels at the end of the study despite supplementation. In a cohort similar to ours, Ish-Shalom et al. [22] found that only half of patients with initial 25OHD nmol/L below $50 \mathrm{nmol} / \mathrm{L}$, and $80 \%$ of those with $25-\mathrm{OHD} 50 \mathrm{nmol} / \mathrm{L}$ and above, achieved the therapeutic target $(75 \mathrm{nmol} / \mathrm{L})$ after 8 -weeks of $1500 \mathrm{IU}$ vitamin $\mathrm{D}_{3}$ daily. In nursing homes residents receiving $600 \mathrm{IU}$ vitamin $\mathrm{D}_{3}$ daily, fewer than $40 \%$ achieved vitamin D levels of $75 \mathrm{nmol} / \mathrm{L}$ after 4 months [23]. Among elderly women with hip fractures receiving either 800 IU vitamin $\mathrm{D}_{3}$ daily or 97,333 IU monthly, $47 \%$ of the daily group and $28 \%$ of the monthly group achieved $75 \mathrm{nmol} /$ $\mathrm{L}$ after 12 months [20]. Therefore other strategies such as a higher daily dose may need to be considered to enable a greater proportion of hip fracture patients to achieve optimal 25-OHD levels.

Achieving adequate 25-OHD levels after hip fracture is important from a therapeutic standpoint and may be needed to ensure optimal effectiveness of bisphosphonates $[13,14]$. In meta-analyses, a minimum daily dose of daily $700 \mathrm{IU}$ vitamin $\mathrm{D}_{3}$ was considered necessary to prevent falls and osteoporotic fractures [34-36].

A number of limitations are acknowledged here. Although, we randomized patients into study groups, we found a significant difference in age among groups. Due to our sample size, and because some patients did not have a baseline measure prior to the bolus dose, we were unable to properly examine patients with greater baseline vitamin D deficiency or insufficiency. We did not examine the seasonal influence on 25-OHD levels since this was a short-term study and the majority of our patients were hospitalized for approximately a third or more of the study period. However, our results are consistent with other studies which have found that high dose vitamin $D_{3}$ is not more effective than daily dosing $[20,22,23] . \mathrm{D}_{3}$ was not used as a loading dose because it is not available in Canada. Further research will need to be conducted to determine if a loading dose of $\mathrm{D}_{3}$ plus daily vitamin $\mathrm{D}_{3}$ is more effective as compared with a loading dose of $\mathrm{D}_{2}$ and to determine the most effective daily dose. In addition, parathyroid hormone levels were not measured so the relationship between the hormone and vitamin D levels could not be described. Examining the efficacy of vitamin D supplementation for the prevention of falls in the first 3 months post-hip fracture would be interesting given recent reports regarding the need for 25-OHD levels to be at $60 \mathrm{nmol} / \mathrm{L}$ for optimal fall prevention [37] and the recent observation that a single, once yearly, very large dose of vitamin $\mathrm{D}_{3}(500,000 \mathrm{IU})$ is associated with an increased risk of fall or fracture [38].

\section{Conclusions}

Our findings reveal that a simple daily 1,000 IU vitamin $\mathrm{D}_{3}$ dosing regimen may be as effective as a regimen that adds a loading dose of vitamin $\mathrm{D}_{2}$ to daily vitamin $\mathrm{D}_{3}$ for increasing 25-OHD levels as early as 4 -weeks. However, more than $25 \%$ of all study patients taking 1,000 IU vitamin $\mathrm{D}_{3}$ (with or without the loading dose) still did not achieve the target 25-OHD level of at least 75 nmol/L. Future studies should examine higher daily doses of vitamin $\mathrm{D}_{3}$ (i.e. 2,000 IU) as well as the benefits of an additional loading dose in patients who are severely deficient.

\section{Acknowledgements}

We thank Madeline Nixon who coordinated data collection and was instrumental in completing this study. The authors would also like to acknowledge and thank: Josephine Baldwin, Pauline Fisher, Jackie Kinch, Diane Lourenco, Donna MacMillian, Ruth McCallum, Liz Piccirillo, Karen Robinson, Gerri Schweinbenz, Erlene Seaborne, Gita Sobhi, and all other staff who assisted in the study at the Henderson Hospital (Wards E4, F4, and 3 Musculoskeletal Rehabilitation), and McMaster University Medical Centre Ward 4 Y. This study was supported by an unrestricted educational grant from Merck Frosst Canada Ltd.

\section{Author details}

'McMaster University, HHSC, St. Peter's Hospital Juravinski Research Centre, 88 Maplewood Avenue Hamilton, ON L8M 1W9, Canada. ${ }^{2}$ University of Waterloo, Department of Kinesiology, University of Waterloo, 200 University Ave W., Waterloo ON N2L 3G1, Canada. ${ }^{3}$ McMaster University, 501-25 Charlton Ave E, Hamilton ON L8N 1Y2, Canada. ${ }^{4}$ McMaster University, HHSC, St. Peter's Hospital Juravinski Research Centre, 88 Maplewood Avenue Hamilton, ON L8M 1W9, Canada. ${ }^{5}$ nniversity of Calgary, University of Calgary Health Sciences Centre, 3330 Hospital Drive N.W., Calgary AB T2N 4N1, Canada. ${ }^{6}$ McMaster University, Henderson Hospital, 711 Concession Street, Section M, First Floor, Room 37, Hamilton ON L8V 1C3, Canada. ${ }^{7}$ McMaster University, 1 Young St. Suite 307, Hamilton ON L8N 1T8, Canada. ${ }^{8}$ McMaster University, 501-25 Charlton Ave E, Hamilton ON L8N 1Y2, Canada.

\section{Authors' contributions}

AP: conceived the study, participated in the study design, and critically revised the manuscript for important intellectual content. CCK: participated in the study design, statistical analysis, interpretation of data, and drafted the manuscript. LG: participated in the study design and critically revised the manuscript for important intellectual content. Gl: participated in the study design, statistical analysis, interpretation of data, and critically revised the manuscript for important intellectual content. JP: participated in the study design and critically revised the manuscript for important intellectual content. DAH: participated in the study design and critically revised the manuscript for important intellectual content. LF: participated in the study design and critically revised the manuscript for important intellectual 
content. JD: participated in the study design and critically revised the manuscript for important intellectual content. JDA: participated in the study design and critically revised the manuscript for important intellectual content. All authors read and approved the final manuscript.

\section{Competing interests}

Alexandra Papaioannou: Honoraria, grants received, or consultancies-Eli Lilly and Company, Merck Frosst, Amgen Inc, The Alliance for Better Bone Health (Procter \& Gamble Pharmaceuticals and sanofi-aventis), Novartis Pharmaceuticals Corporation, Servier.

Courtney C. Kennedy: author declares she has no competing interests. Lora Giangregorio: author declares she has no competing interests. George loannidis: author declares he has no competing interests. Janet Pritchard: author declares she has no competing interests. David A. Hanley: Honoraria, grants received, or consultancies-Eli Lilly and Company, Merck Frosst, Amgen Inc, The Alliance for Better Bone Health (Procter \& Gamble Pharmaceuticals and sanofi-aventis), Novartis Pharmaceuticals Corporation, Servier.

Leonardo Farrauto: author declares he has no competing interests. Justin DeBeer: author declares he has no competing interests. Jonathan D. Adachi: Honoraria, grants received, or consultancies: - Eli Lilly and Company, Merck Frosst, Amgen Inc, The Alliance for Better Bone Health (Procter \& Gamble Pharmaceuticals and sanofi-aventis), Novartis

Pharmaceuticals Corporation, GlaxoSmithKline Consumer Healthcare, Servier, Roche, Servier, Wyeth.

Received: 17 January 2011 Accepted: 20 June 2011 Published: 20 June 2011

\section{References}

1. Holick MF, Chen TC: Vitamin D deficiency: A worldwide problem with health consequences. Am J Clin Nutr 2008, 87:1080S-6S.

2. Lips $P$ : Vitamin $D$ deficiency and secondary hyperparathyroidism in the elderly: Consequences for bone loss and fractures and therapeutic implications. Endocr Rev 2001, 22:477-501.

3. Dawson-Hughes B, Heaney RP, Holick MF, Lips P, Meunier PJ, Vieth R: Estimates of optimal vitamin D status. Osteoporos Int 2005, 16:713-6.

4. Hanley DA, Cranney A, Jones G, Whiting S, Leslie WD, the Guidelines Committee of the Scientific Advisory Council of Osteoporosis Canada: Vitamin $D$ in adult health and disease: A review and guideline statement from osteoporosis canada. CMAJ 2010, 182:E610-8.

5. Dawson-Hughes B, Mithal A, Bonjour JP, Boonen S, Burckhardt P, Fuleihan GE, et al: IOF position statement: Vitamin D recommendations for older adults. Osteoporos Int 2010.

6. Bischoff-Ferrari HA, Willett WC, Wong JB, Giovannucci E, Dietrich T, DawsonHughes B: Fracture prevention with vitamin D supplementation: A metaanalysis of randomized controlled trials. JAMA 2005, 293:2257-64.

7. Tang BM, Eslick GD, Nowson C, Smith C, Bensoussan A: Use of calcium or calcium in combination with vitamin $D$ supplementation to prevent fractures and bone loss in people aged 50 years and older: A metaanalysis. Lancet 2007, 370:657-66.

8. Bischoff-Ferrari HA, Dawson-Hughes B, Willett WC, Staehelin HB, Bazemore MG, Zee RY, et al: Effect of vitamin D on falls: A meta-analysis. JAMA 2004, 291:1999-2006.

9. Bischoff-Ferrari H: Vitamin D: What is an adequate vitamin D level and how much supplementation is necessary? Best Pract Res Clin Rheumatol 2009, 23:789-95

10. Bischoff-Ferrari HA, Dawson-Hughes B, Staehelin HB, Orav JE, Stuck AE, Theiler $R$, et al: Fall prevention with supplemental and active forms of vitamin D: A meta-analysis of randomised controlled trials. BMJ 2009, 339:b3692.

11. Bischoff-Ferrari HA, Willett WC, Wong JB, Stuck AE, Staehelin HB, Orav E et al: Prevention of nonvertebral fractures with oral vitamin $D$ and dose dependency: A meta-analysis of randomized controlled trials. Arch Intern Med 2009, 169:551-61.

12. Kanis JA, Johnell $O$, De Laet $C$, Johansson $H$, Oden $A$, Delmas $P$, et al: $A$ meta-analysis of previous fracture and subsequent fracture risk. Bone 2004, 35:375-82.

13. Mastaglia SR, Pellegrini GG, Mandalunis PM, Gonzales Chaves MM, Friedman SM, Zeni SN: Vitamin D insufficiency reduces the protective effect of bisphosphonate on ovariectomy-induced bone loss in rats. Bone 2006, 39:837-44.

14. Adami S, Giannini S, Bianchi G, Sinigaglia L, Di Munno O, Fiore CE, et al: Vitamin $D$ status and response to treatment in post-menopausal osteoporosis. Osteoporos Int 2009, 20:239-44.

15. Gallacher SJ, McQuillian C, Harkness M, Finlay F, Gallagher AP, Dixon T: Prevalence of vitamin $D$ inadequacy in scottish adults with nonvertebral fragility fractures. Curr Med Res Opin 2005, 21:1355-61.

16. Beringer $T$, Heyburn G, Finch M, McNally C, McQuilken M, Duncan M, et al: Prevalence of vitamin $D$ inadequacy in belfast following fragility fracture. Curr Med Res Opin 2006, 22:101-5.

17. Simonelli C, Weiss TW, Morancey J, Swanson L, Chen YT: Prevalence of vitamin $D$ inadequacy in a minimal trauma fracture population. Curr Med Res Opin 2005, 21:1069-74.

18. Pieper CF, Colon-Emeric C, Caminis J, Betchyk K, Zhang J, Janning C, et al: Distribution and correlates of serum 25 -hydroxyvitamin $D$ levels in a sample of patients with hip fracture. Am J Geriatr Pharmacother 2007, 5:335-40.

19. Bakhtiyarova S, Lesnyak O, Kyznesova N, Blankenstein MA, Lips P: Vitamin D status among patients with hip fracture and elderly control subjects in yekaterinburg, russia. Osteoporos Int 2006, 17:441-6.

20. Pekkarinen T, Valimaki W, Aarum S, Turpeinen U, Hamalainen E, Loyttyniemi $E$, et al: The same annual dose of $292000 \mathrm{IU}$ of vitamin D (cholecalciferol) on either daily or four monthly basis for elderly women: 1 -year comparative study of the effects on serum 25(OH)D concentrations and renal function. Clin Endocrinol (Oxf) 2010, 72:455-61.

21. Przybelski R, Agrawal S, Krueger D, Engelke JA, Walbrun F, Binkley N: Rapid correction of low vitamin D status in nursing home residents. Osteoporos Int 2008, 19:1621-8.

22. Ish-Shalom S, Segal E, Salganik T, Raz B, Bromberg IL, Vieth R: Comparison of daily, weekly, and monthly vitamin D3 in ethanol dosing protocols for two months in elderly hip fracture patients. J Clin Endocrinol Metab 2008, 93:3430-5.

23. Chel V, Wijnhoven HA, Smit JH, Ooms M, Lips P: Efficacy of different doses and time intervals of oral vitamin $D$ supplementation with or without calcium in elderly nursing home residents. Osteoporos Int 2008, 19:663-71.

24. Bacon CJ, Gamble GD, Horne AM, Scott MA, Reid IR: High-dose oral vitamin D3 supplementation in the elderly. Osteoporos Int 2009, 20:1407-15.

25. Armas LA, Hollis BW, Heaney RP: Vitamin D2 is much less effective than vitamin D3 in humans. J Clin Endocrinol Metab 2004, 89:5387-91.

26. Scillitani A, Minisola S: Short and long-term variations in serum calciotropic hormones after a single very large does of ergocalciferol (vitmain D2) or cholecalciferol (vitamin D3) in the elderly. J Clin Endocrinol Metabl 2008, 93:3015-20.

27. Trang HM, Cole DE, Rubin LA, Pierratos A, Siu S, Vieth R: Evidence that vitamin $D 3$ increases serum 25-hydroxyvitamin $D$ more efficiently than does vitamin D2. Am J Clin Nutr 1998, 68:854-8.

28. Charlson ME, Pompei $P$, Ales KL, Mackenzie CR: A new method of classifying prognostic comorbidity in longitudinal studies: Development and validation. J Chronic Dis 1987, 40:373-83.

29. Schulz KF, Altman DG, Moher D, CONSORT Group: CONSORT 2010 statement: Updated guidelines for reporting parallel group randomised trials. BMJ 2010, 340:332

30. Hackman KL, Gagnon C, Briscoe RK, Lam S, Anpalahan M, Ebeling PR: Efficacy and safety of oral continuous low-dose versus short-term highdose vitamin D: a prospective randomised trial conducted in a clinical setting. Med J Aust 2010, 192:686-9.

31. Harwood RH, Sahota O, Gaynor K, Masud T, Hosking DJ, Nottingham Neck of Femur (NONOF) Study: A randomised, controlled comparison of different calcium and vitamin $\mathrm{D}$ supplementation regimens in elderly women after hip fracture: The nottingham neck of femur (NONOF) study. Age Ageing 2004, 33:45-51.

32. Romagnoli E, Mascia ML, Cipriani C, Fassino V, Mazzei F, D'Erasmo E, et al: Short and long-term variations in serum calciotropic hormones after a single very large dose of ergocalciferol (vitamin D2) or cholecalciferol (vitamin D3) in the elderly. $J$ Clin Endocrinol Metab 2008, 93:3015-20.

33. Di Monaco M, Castiglioni C, Valler F, Di Monaco R, Tappero R: Appendicular lean mass does not mediate the significant association between vitamin D status and functional outcome in hip fracture women. Arch Phys Med Rehab 2011, 92:271-6. 
34. Bischoff HA, Stahelin HB, Dick W, Akos R, Knecht M, Salis C, et al: Effects of vitamin $D$ and calcium supplementation on falls: A randomized controlled trial. J Bone Miner Res 2003, 18:343-51.

35. Bischoff-Ferrari HA, Dawson-Hughes B, Willett WC, Staehelin HB, Bazemore MG, Zee RY, et al: Effect of vitamin D on falls: A meta-analysis. JAMA 2004, 291:1999-2006.

36. Bischoff-Ferrari HA, Willett WC, Wong JB, Giovannucci E, Dietrich T, DawsonHughes B: Fracture prevention with vitamin D supplementation: A metaanalysis of randomized controlled trials. JAMA 2005, 293:2257-64.

37. Bischoff-Ferrari HA, Dawson-Hughes B, Staehelin HB, Orav JE, Stuck AE, Theiler R, et al: Fall prevention with supplemental and active forms of vitamin D: A meta-analysis of randomised controlled trials. BMJ 2009, 339:b3692.

38. Sanders KM, Stuart AL, Williamson EJ, Simpson JA, Kotowicz MA, Young D, et al: Annual high-dose oral vitamin $D$ and falls and fractures in older women: A randomized controlled trial. JAMA 2010, 303:1815-22.

Pre-publication history

The pre-publication history for this paper can be accessed here: http://www.biomedcentral.com/1471-2474/12/135/prepub

doi:10.1186/1471-2474-12-135

Cite this article as: Papaioannou et al: A randomized controlled trial of vitamin $D$ dosing strategies after acute hip fracture: No advantage of loading doses over daily supplementation. BMC Musculoskeletal Disorders 2011 12:135.

\section{Submit your next manuscript to BioMed Central} and take full advantage of:

- Convenient online submission

- Thorough peer review

- No space constraints or color figure charges

- Immediate publication on acceptance

- Inclusion in PubMed, CAS, Scopus and Google Scholar

- Research which is freely available for redistribution

Submit your manuscript at www.biomedcentral.com/submit 